\title{
A NEW DRAINAGE BASIN DELINEATION FOR THE SOUTHERN PATAGONIAN ICE FIELD BASED ON TERRASAR-X VELOCITIES AND TANDEM-X ELEVATIONS
}

\author{
L. Krieger ${ }^{1, *}$, E. Johnson ${ }^{1}$, D. Floricioiu ${ }^{1}$ \\ ${ }^{1}$ Remote Sensing Technology Institute, German Aerospace Center, Germany - lukas.krieger@ dlr.de
}

KEY WORDS: Drainage basins, Catchments, Patagonian Ice Field

\begin{abstract}
:
The drainage basins or catchments for the Patagonian Ice Field are part of glacier inventories like the Randolph Glacier Inventory (RGI) or the Global Land Ice Measurements from Space (GLIMS). These catchments are used in many glaciological studies for integrating remote sensing measurements over the area of a single glacier. An accurate basin boundary delineation is therefore important for applications like mass balance measurements for individual glaciers in Patagonia. Here we investigate existing catchment delineations of the Southern Patagonian Ice Field (SPI) with a modified watershed algorithm that is capable of including ice velocity measurements from SAR offset tracking during the delineation process. The classical watershed delineation is performed using only a DEM. We show that apart from the basins of Bernardo, Greve, Tempano and Occidental there is no dependence of the basin boundary on the measured ice velocity direction and that the glaciers of SPI flow in the direction of the steepest surface slope of modern high resolution DEMs like the TDM global DEM or SRTM. Additionally, a map of basin probabilities has been produced, which highlights several locations on the ice field where the delineation of the exact basin boundary is difficult.
\end{abstract}

\section{INTRODUCTION}

Glaciers are important contributors to the global sea level rise. In order to better understand the variations in ice flow dynamics and their response to climate change, the estimation of the total glacier mass balance and its individual components are necessary. These are usually reported on the basin scale and are partitioned in dynamic mass loss through calving and the glacier surface mass balance. Especially for the surface mass balance and if volumetric changes are measured, accurate delineations of the glacier drainage basins are needed.

The region analysed here is the Southern Patagonian Ice Field (SPI), at the southern part of the American Andes. It represents the largest temperate ice mass in the Southern Hemisphere, covering approximately $48.3^{\circ} \mathrm{S}$ to $51.6^{\circ} \mathrm{S}$ along $73.5^{\circ} \mathrm{W}$ with a mean width of $45 \mathrm{~km}$ (Aniya et al., 1996). This ice field is susceptible to environmental changes climate change.

The first glacier inventory covering the whole SPI was published by the US army using aerial survey (1944-45) (Mercer, 1965). More recently (Aniya et al., 1996) used Landsat imagery from 1986, complemented by topographic maps from the Chilean "Instituto Geográfico Milita" and stereoscopic areal photographs to identify the ice divides. Complicated areas on the flat plateau e.g. "Meseta de los cuatro glaciares" between PioXI, O'Higgins, Chico and Viedma resulted in uncertain delineations. This divide was also addressed using the ASTER GDEM and GPS measurements (Rivera et al., 2005). (Rignot et al., 2003) used SRTM to draw the drainage boundaries. Finally, a different approach was performed by (Casassa, 2014, Chapter 27) introducing an automatic basin delineation software with the SRTM DEM and ASTER GDEM as inputs. Available through the Global Land Ice Measurements from Space (GLIMS) project are two versions of delineated catchments. These are worldwide glacier inventories which also include glacier basins for SPI:

\footnotetext{
* Corresponding author
}

- The Randolph Glacier Inventory (RGI) in which the SPI delineations were made by (Angelis, 2014) using a manual delineation outlined after visual interpretation of Landsat 5 images.

- The GLIMS Inventory which includes catchment delineations of many different authors and also maps internal rocks, debris cover, proglacial lakes, etc.

Usually catchments for water routing are delineated by a watershed algorithm on a DEM (Vincent, Soille, 1991). For glacial ice however, there is a possibility that the ice flow direction is not in the same direction as the surface slope because of glacier instabilities, large bedrock features or the interaction of ice masses. This could potentially direct the actual ice flow away from the DEM aspect angle and alter the basin boundaries. For ice sheets it has been established, that a combined approach of measured ice velocity as well as surface slope directions from the DEM are necessary for an accurate catchment delineation (Rignot et al., 2000) (Mouginot, Rignot, 2019) (Krieger et al., 2020).

Here we investigate existing basins of SPI with this methodology and compare the delineation to existing catchments that are part of the RGI and exceed $35 \mathrm{~km}^{2}$ in area.

\section{DATA \& METHODS}

Two independent types of data have been utilised for the delineation of the individual glacier catchments which are both used to extract information about the ice flow direction. As elevation data, the TDM global DEM over the Patagonian Ice Field has been selected (Rizzoli et al., 2017). The DEM has been edited to remove remaining errors due to phase unwrapping and small holes were filled with elevation data from SRTM data (Crippen et al., 2016). As discussed in (Paterson, 2016) the DEM was smoothed with a sliding average filter of a width equal to 5-times the local ice thickness in order measure flow directions 
from the DEM aspect angle. For this purpose, the ice thickness has been calculated from the TDM global DEM and bedrock elevations from (Millan et al., 2019). As a comparison dataset we used a second DEM based on SRTM elevations which was processed by (Crippen et al., 2016) and which was filtered with the same ice thickness based procedure.

Ice velocities from SAR offset tracking are the second source to measure ice flow direction. The ice velocities have been processed from repeat pass TerraSAR-X (TSX) acquisitions in the glaciological accumulation season $(2016,2018)$ and ablation season (2017). We used normalised cross-correlation to track glacier features. Estimated shifts in range and azimuth direction have been geocoded with precise orbit information and the TanDEM-X global DEM. Subsequently, the maps of ice surface velocity were filtered based on the ice velocity magnitude and flow direction for outlier elimination according to (Lüttig et al., 2017).

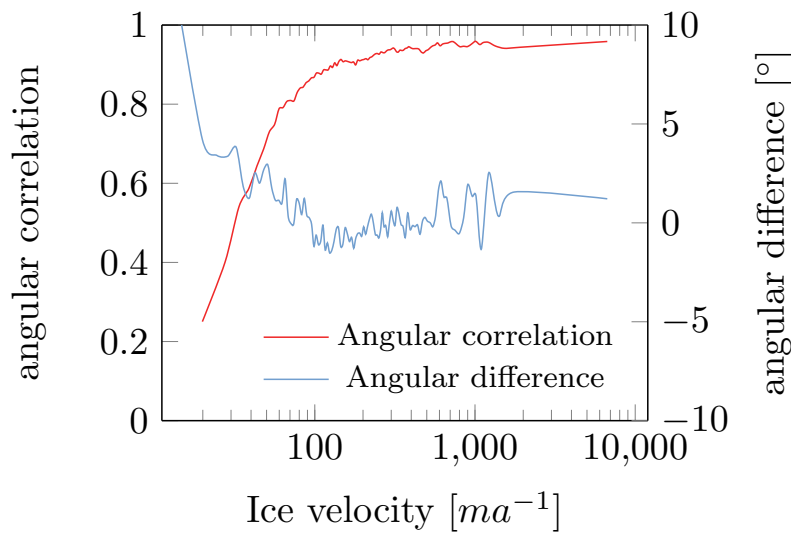

Figure 1. Correlation and mean difference of the TanDEM-X global DEM aspect angle (direction of steepest slope) and the flow angle of the TSX velocity vectors. The comparison is carried out over the entire SPI area for velocity bins that contain an equal number of points.

The two datasets were interpolated on the same grid of $100 \mathrm{~m}$ pixel size with a cubic spline interpolation. Then, in order to define seed pixels that mark the start of the basin delineation process, we selected all glaciers with an area larger than $35 \mathrm{~km}^{2}$ as defined in the RGI and marked all pixels touching the iceland interface on the glacier termini (RGI Consortium, 2017). A modified watershed algorithm was developed by (Krieger et al., 2020) which was demonstrated to delineate individual glacier catchments on ice sheets. Here we used the previously defined seed points as input and processed 4 combinations of the two DEMs (TDM, SRTM) and additional velocity information (TSX, no velocity). We compared the ice flow directions that are derived from the TDM global DEM aspect angle with those from the measured SAR offset tracking and plotted them over the ice velocity magnitude in Figure 1. With increasing ice velocities, the correlation between the two angle measurements is increasing, which indicates that there are no major differences between the DEM aspect angles and the actual ice flow direction at high velocities $>100 \mathrm{~m} \mathrm{a}^{-1}$. This is a difference to the pattern found for ice sheets and might be due to the fact that the strong topography on the SPI restricts the ice flow more (Krieger et al., 2020). Moreover, the angular differences between the two measurements are also close to $0^{\circ}$ for velocity magnitudes exceeding $100 \mathrm{~m} \mathrm{a}^{-1}$, which was therefore used as a threshold to switch between slope information from the DEM and the SAR offset tracking direction during the modified watershed algorithm.

We performed a Monte Carlo experiment with $N=5000$ runs for all 4 different input dataset combinations by adding Gaussian noise to the DEM, the $\mathrm{x}$ - and $\mathrm{y}$ - velocity components as well as the velocity magnitude threshold of $100 \mathrm{~m} \mathrm{a}^{-1}$. Due to the steeper slopes on the Patagonian Ice Field compared to the Greenland study area in Greenland (Krieger et al., 2020) we increased the uncertainty of the DEM elevations in the Monte Carlo experiment to $\sigma_{D E M}=25 \mathrm{~m}$. The uncertainty for the ice velocity components was set to $\sigma_{v e l}=25 \mathrm{~m} \mathrm{a}^{-1}$ and the one of the velocity magnitude threshold to $\sigma_{t}=10 \mathrm{~m} \mathrm{a}^{-1}$.

\section{RESULTS \& DISCUSSION}
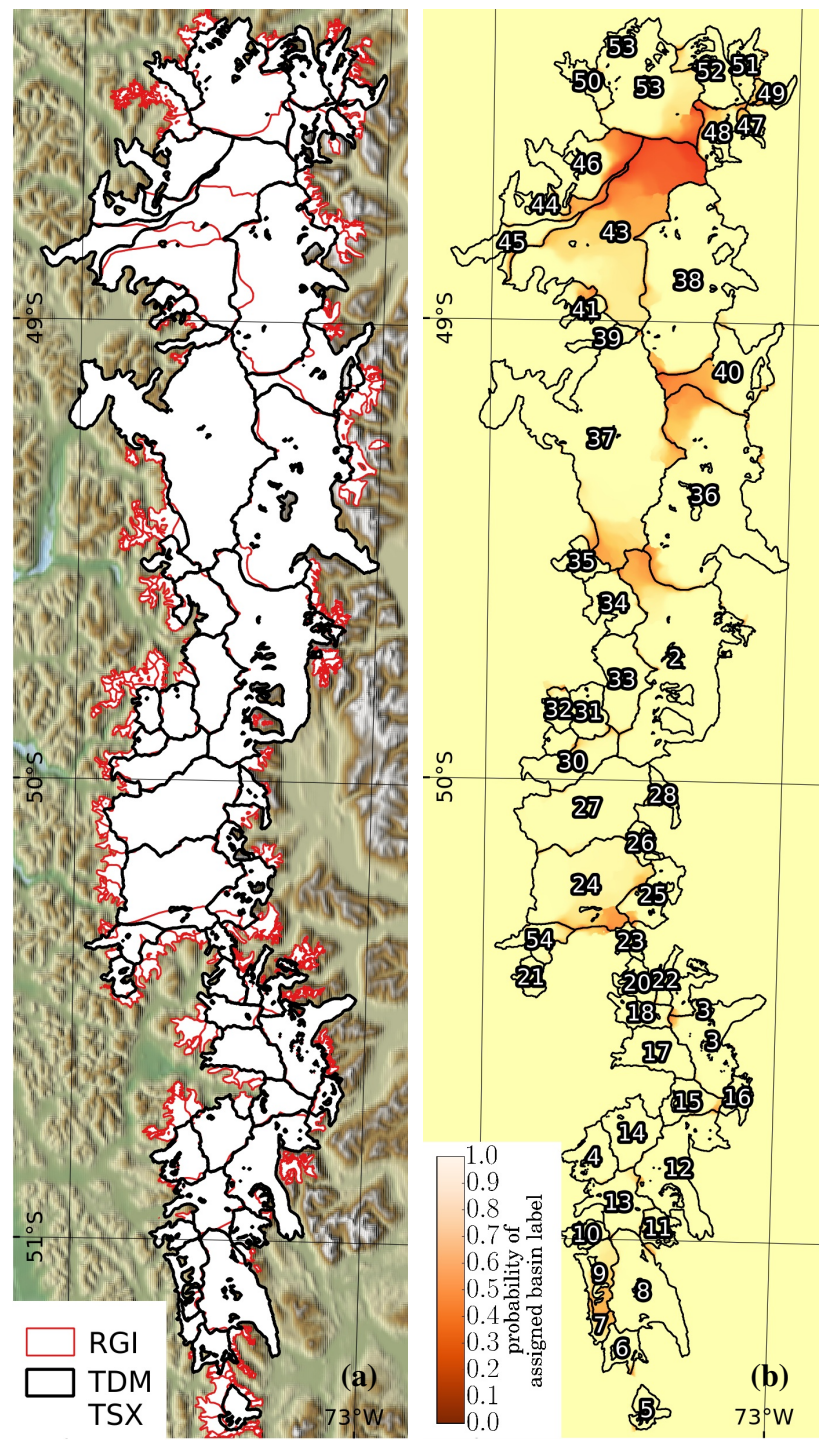

Figure 2. The SPI and its (a) catchment delineations in the RGI (red) with our delineations from the TDM global DEM and TSX velocities (black). (b) the corresponding basin probabilities for the TDM/TSX drainage basin delineation.

In Figure 2(a) we visualised the delineation based on the TDM global DEM including TSX ice velocities and compared it to the existing RGI delineation. Details are reported in Table 1, 
Table 1. Drainage basin areas $A$ and their respective differences to the RGI delineation (e.g. TDM/TSX - RGI) $\Delta A$ for each numbered glacier as in Figure 2(b).

\begin{tabular}{|c|c|c|c|c|c|c|c|c|c|c|}
\hline \# & Glacier name & $\mathrm{RGI}\left[\mathrm{km}^{2}\right]$ & TDM/ & $\mathrm{SX}\left[\mathrm{km}^{2}\right]$ & TDM & $\left.\mathrm{km}^{2}\right]$ & SRTM & $\mathrm{SX}\left[\mathrm{km}^{2}\right]$ & SRTM & $\left.\mathrm{km}^{2}\right]$ \\
\hline & & $A$ & $A$ & $\Delta A$ & $A$ & $\Delta A$ & A & $\Delta A$ & $A$ & $\Delta A$ \\
\hline 37 & Pio XI & 1,235 & 1,229 & -6 & 1,230 & -5 & 1,235 & 1 & 1,236 & 1 \\
\hline 36 & Viedma & 975 & 946 & -29 & 941 & -35 & 933 & -43 & 936 & -39 \\
\hline 2 & Upsala + Cono & 838 & 800 & -38 & 793 & -45 & 791 & -47 & 785 & -53 \\
\hline 38 & OHiggins & 762 & 813 & 51 & 814 & 52 & 813 & 51 & 814 & 52 \\
\hline 46 & Bernardo & 541 & 265 & -276 & 540 & -1 & 258 & -283 & 575 & 34 \\
\hline 53 & Jorge Montt & 489 & 531 & 43 & 524 & 36 & 491 & 2 & 478 & -11 \\
\hline 27 & Penguin & 470 & 468 & -2 & 469 & -1 & 468 & -2 & 468 & -2 \\
\hline 43 & Greve & 429 & 865 & 437 & 637 & 208 & 869 & 440 & 641 & 213 \\
\hline 24 & Europa & 406 & 476 & 70 & 462 & 57 & 476 & 70 & 462 & 56 \\
\hline 44 & Tempano & 335 & 131 & -204 & 97 & -238 & 161 & -174 & 100 & -235 \\
\hline 8 & Tyndall & 310 & 307 & -2 & 308 & -2 & 307 & -3 & 307 & -2 \\
\hline 12 & Grey + Dickson & 308 & 315 & 8 & 316 & 8 & 315 & 7 & 315 & 7 \\
\hline 3 & Perito Moreno & 263 & 255 & -8 & 253 & -10 & 257 & -7 & 255 & -8 \\
\hline 40 & Chico & 239 & 279 & 39 & 293 & 54 & 295 & 56 & 298 & 59 \\
\hline 45 & Occidental & 235 & 143 & -92 & 137 & -98 & 143 & -92 & 131 & -105 \\
\hline 33 & HPS 13 & 214 & 213 & -1 & 214 & -0 & 213 & -0 & 214 & -0 \\
\hline 17 & HPS 31 & 167 & 160 & -7 & 159 & -8 & 158 & -9 & 157 & -10 \\
\hline 54 & Guilardi & 167 & 87 & -79 & 89 & -78 & 87 & -79 & 89 & -78 \\
\hline 34 & HPS 12 & 165 & 149 & -16 & 149 & -16 & 151 & -14 & 152 & -13 \\
\hline 52 & Lucia & 164 & 160 & -4 & 157 & -7 & 162 & -2 & 158 & -6 \\
\hline 13 & Amalia & 163 & 161 & -2 & 161 & -3 & 162 & -2 & 162 & -2 \\
\hline 30 & HPS 19 & 163 & 168 & 5 & 168 & 5 & 168 & 5 & 168 & 5 \\
\hline 14 & HPS 34 & 153 & 157 & 4 & 157 & 4 & 158 & 4 & 158 & 4 \\
\hline 25 & Spegazzini & 120 & 136 & 16 & 138 & 18 & 137 & 17 & 137 & 17 \\
\hline 4 & Asia & 114 & 117 & 4 & 117 & 4 & 117 & 3 & 117 & 3 \\
\hline 15 & Calvo & 104 & 100 & -5 & 100 & -4 & 100 & -4 & 100 & -4 \\
\hline 48 & Bravo & 104 & 111 & 7 & 113 & 9 & 117 & 14 & 116 & 12 \\
\hline 31 & HPS 15 & 99 & 104 & 4 & 104 & 4 & 104 & 4 & 104 & 4 \\
\hline 50 & Ofhidro & 83 & 75 & -8 & 75 & -8 & 76 & -7 & 76 & -7 \\
\hline 51 & Pascua & 81 & 80 & -1 & 80 & -1 & 80 & -1 & 80 & -1 \\
\hline 18 & HPS 29 & 79 & 83 & 4 & 83 & 4 & 84 & 4 & 84 & 4 \\
\hline 6 & HPS 41 & 77 & 71 & -6 & 70 & -6 & 71 & -5 & 71 & -6 \\
\hline 11 & Pingo & 70 & 61 & -9 & 61 & -9 & 61 & -9 & 61 & -9 \\
\hline 20 & HPS 28 & 69 & 69 & 0 & 69 & 0 & 69 & 1 & 69 & 1 \\
\hline 35 & HPS 10 & 68 & 67 & -1 & 67 & -0 & 66 & -2 & 66 & -1 \\
\hline 19 & Ameghino & 55 & 64 & 9 & 66 & 10 & 64 & 9 & 66 & 10 \\
\hline 5 & Balmaceda & 55 & 54 & -1 & 54 & -1 & 55 & -0 & 55 & -0 \\
\hline 28 & Agassiz & 54 & 53 & -2 & 53 & -2 & 53 & -2 & 52 & -2 \\
\hline 39 & HPS 9 & 54 & 50 & -4 & 50 & -4 & 50 & -4 & 50 & -4 \\
\hline 10 & HPS 38 & 53 & 49 & -4 & 49 & -4 & 48 & -4 & 48 & -4 \\
\hline 26 & Onelli & 49 & 47 & -2 & 47 & -2 & 47 & -2 & 47 & -2 \\
\hline 16 & Frias & 47 & 52 & 6 & 52 & 6 & 51 & 5 & 51 & 4 \\
\hline 49 & Oriental & 46 & 48 & 1 & 47 & 1 & 48 & 2 & 47 & 1 \\
\hline 22 & Mayo & 41 & 41 & -0 & 41 & -0 & 41 & -0 & 41 & -0 \\
\hline 47 & Mellizo Sur & 37 & 31 & -7 & 29 & -8 & 31 & -7 & 29 & -9 \\
\hline 41 & HPS 8 & 35 & 38 & 3 & 38 & 3 & 38 & 3 & 38 & 3 \\
\hline
\end{tabular}

which contains area statistics of all catchments and their respective difference to RGI for all 4 different input data combinations. Overall the catchment areas show large similarities visually and with median area differences of $-1.1 \mathrm{~km}^{2}$ to $-1.4 \mathrm{~km}^{2}$ depending on the delineation. This shows that most of the basin boundaries are clearly defined and only the glaciers Bernardo, Greve, Tempano and Occidental show differences that exceed $100 \mathrm{~km}^{2}$.

Except for the basins in the north-west there are no clear differences between the delineations using only DEM information versus the ones that include ice flow directions from TSX offset tracking. The strong topography of the bedrock under the ice field results in gravity induced flow along the steepest slope of the smoothed surface elevations in the DEM leading to high correlation values of the DEM aspect angle and measured ice flow direction. Additionally, on ice fields, most neighbouring glaciers flow through separate valleys and do not form ice streams of converging and diverging ice flow. This is why, contrary to the ice sheets, there is also no decrease of the angle correlations in Figure 1 for higher ice velocities where the ice flow is not necessarily aligned with the DEM aspect angle. One notable exception is that delineations including ice velocity measurements would allow to separate the ice flow to the northern and southern terminus of Pio XI, which is not possible using only a DEM. However, because Pio XI switches the main flow direction between the north and south facing terminus and it is also considered as one basin in the RGI delineation, this experiment has not been performed here.

The basin probabilities in Figure 2(b) are a direct output of the Monte Carlo experiment for each input dataset combination. They highlight the regions where the delineation of the exact basin boundary is difficult and varies based on the additional Gaussian noise that was added during the Monte Carlo experiment with the standard deviations $\sigma_{D E M}, \sigma_{v e l}$ and $\sigma_{t}$. Basins that are delineated with a low probability are often characterised by gentle slopes which complicates the exact bound- 
ary delineation. Apart from the already mentioned basins in the north-west, such cases were found at the drainage divide between Chico and Viedma, Upsala and PioXI as well as several smaller glaciers in the south (See Figure 2(b)). The Monte Carlo analysis can explain some of the differences between the RGI and our delineation especially between the glaciers with basin number 38 and 43 as well as 36 and 40 .

\section{CONCLUSION}

In this study we find that most basin boundaries of the glaciers on the SPI are accurately defined in the RGI. We show that especially the basins of Bernardo, Greve, Tempano and Occidental in the north-west are difficult to delineate and that depending on the delineation, large parts of the accumulation zone might be draining to one of the neighbouring glaciers. This could result in erroneous mass balances if the measurements are reported for the individual glaciers. We also highlight several regions that are separated by especially flat slopes including the plateau between Viedma and Chico or Pio XI and Upsala. In these areas, a focused collection of InSAR derived ice velocities from crossing orbits could help to identify the exact drainage divide.

\section{ACKNOWLEDGEMENTS}

The TanDEM-X global DEM tiles were provided by DLR under the research proposal DEM_GLAC0787. The TerraSAR$\mathrm{X}$ scenes were provided by DLR under the research proposals ARC_HYD3550 and HYD2671.

\section{REFERENCES}

Angelis, H. D., 2014. Hypsometry and Sensitivity of the Mass Balance to Changes in Equilibrium-Line Altitude: The Case of the Southern Patagonia Icefield. Journal of Glaciology, 60(219), 14-28.

Aniya, M., Sato, H., Naruse, R., Skvarca, P., Casassa, G., 1996. The Use of Satellite and Airborne Imagery to Inventory Outlet Glaciers of the Southern Patagonia Icefield, South America. Photogrammetric Engineering and Remote Sensing, 62(12).

Casassa, G., 2014. Global Land Ice Measurements from Space. Geophysical Sciences, Springer-Verlag, Berlin Heidelberg.

Crippen, R., Buckley, S., Belz, E., Gurrola, E., Hensley, S., Kobrick, M., Lavalle, M., Martin, J., Neumann, M., Nguyen, Q., Rosen, P., Shimada, J., Simard, M., Tung, W., 2016. NASADEM Global Elevation Model: Methods and Progress.

Krieger, L., Floricioiu, D., Neckel, N., 2020. Drainage Basin Delineation for Outlet Glaciers of Northeast Greenland Based on Sentinel-1 Ice Velocities and TanDEM-X Elevations. Remote Sensing of Environment, 237, 111483.

Lüttig, C., Neckel, N., Humbert, A., 2017. A Combined Approach for Filtering Ice Surface Velocity Fields Derived from Remote Sensing Methods. Remote Sensing, 9(10), 1062.

Mercer, J. H., 1965. Glacier Variations in Southern Patagonia. Geographical Review, 55(3), 390-413.

Millan, R., Rignot, E., Rivera, A., Martineau, V., Mouginot, J., Zamora, R., Uribe, J., Lenzano, G., Fleurian, B. D., Li, X., Gim, Y., Kirchner, D., 2019. Ice Thickness and Bed Elevation of the Northern and Southern Patagonian Icefields. Geophysical Research Letters, 46(12), 6626-6635.
Mouginot, J., Rignot, E., 2019. Glacier Catchments/Basins for the Greenland Ice Sheet. Published: UC Irvine Dash.

Paterson, W. S. B., 2016. The Physics of Glaciers. Elsevier.

RGI Consortium, 2017. Randolph Glacier Inventory - A Dataset of Global Glacier Outlines: Version 6.0. Published: Technical Report, Global Land Ice Measurements from Space, Colorado, USA. Digital Media.

Rignot, E., Buscarlet, G., Csathó, B., Gogineni, S., Krabill, W., Schmeltz, M., 2000. Mass Balance of the Northeast Sector of the Greenland Ice Sheet: A Remote-Sensing Perspective. Journal of Glaciology, 46(153), 265-273.

Rignot, E., Rivera, A., Casassa, G., 2003. Contribution of the Patagonia Icefields of South America to Sea Level Rise. Science, 302(5644), 434-437.

Rivera, A., Casassa, G., Bamber, J., Kääb, A., 2005. IceElevation Changes of Glaciar Chico, Southern Patagonia, Using ASTER DEMs, Aerial Photographs and GPS Data. J. Glaciol., 51(172), 105-112.

Rizzoli, P., Martone, M., Gonzalez, C., Wecklich, C., Borla Tridon, D., Bräutigam, B., Bachmann, M., Schulze, D., Fritz, T., Huber, M., Wessel, B., Krieger, G., Zink, M., Moreira, A., 2017. Generation and Performance Assessment of the Global TanDEM-X Digital Elevation Model. ISPRS Journal of Photogrammetry and Remote Sensing, 132, 119-139.

Vincent, L., Soille, P., 1991. Watersheds in Digital Spaces: An Efficient Algorithm Based on Immersion Simulations. IEEE Transactions on Pattern Analysis and Machine Intelligence, 13(6), 583-598. 